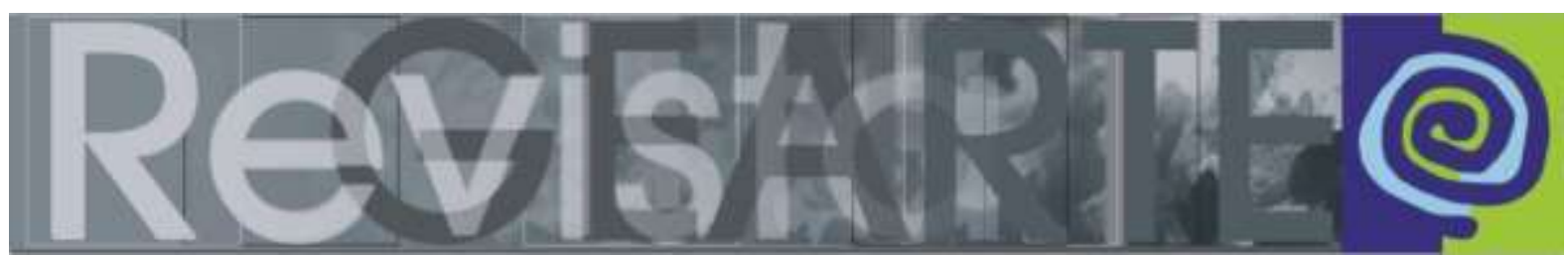

ISSN 2357-9854

\title{
Relação entre verbal e visual na construção do discurso prescritivo na revista Capricho
}

\author{
Letícia Nassar Matos Mesquita (UFES - Brasil) \\ Moema Lucia Martins Rebouças (UFES - Brasil)
}

\begin{abstract}
RESUMO
Uma efusão de cores, formas, imagens e palavras, esmeradamente distribuídas em uma superfície alva e leve, despertam a atenção de um público ávido por saber a respeito de namoro, bullying, maquiagem, roupa e diversão. Trata-se da publicação para jovens mais vendida no Brasil e há mais tempo no mercado: Capricho. Este artigo, então, tem como objetivo analisar o modo como a revista, a partir da relação entre verbal escrito e visual, constrói um discurso prescritivo visualmente atrativo, que apresenta à adolescente os modos de ser e parecer que devem ser seguidos para ser aceita em seus grupos. Os exemplares em estudo são de janeiro de 2010 a dezembro de 2011, com foco na capa. Os estudos da dimensão figurativa e plástica em textos sincréticos, de acordo com a metodologia da semiótica francesa, embasam nossas análises.
\end{abstract}

PALAVRAS-CHAVE

Revista feminina. Linguagens visual e verbal. Semiótica francesa.

\section{ABSTRACT}

An effusion of colors, shapes, images and words, carefully spread in a fair and light surface, calls the attention of an audience avid to know more about dating, bullying, makeup, fashion and fun. This is the bestselling magazine for young people in Brazil: Capricho. The objective of this article is to analyze how this magazine, based on the relation between the written text and the visual aspects, builds a prescriptive and visually attractive speech to present teenagers the ways to be and to look, that should be followed to be part of certain groups. The issues studied are from January/2010 to December/2011, focusing on the front cover. Studies about the figurative and plastic dimensions in syncretic texts, according to the methodology of French semiotic, are the basis of our analyses.

KEYWORDS

Female magazine. Visual and verbal languages. French semiotic.

\section{Introdução}

A Capricho é a revista destinada ao público juvenil mais vendida no Brasil. Nos anos em que exemplares de nossas análises circularam, janeiro de 2010 a dezembro de 2011, a circulação era quinzenal ${ }^{1}$, contava com aproximadamente 90 páginas e seus mais de 207 mil exemplares por edição atendiam a 2,5 milhões de leitoras. Das suas 32 seções, duas serão analisadas em nosso artigo, Busca e Look. Porém, é com

\footnotetext{
${ }^{1}$ A partir de 2014, após 18 anos de periodicidade quinzenal, a publicação passou a ser mensal. Boa parte das suas leitoras migraram para diferentes plataformas digitais: o site da revista, o Facebook, o Twitter, o Instagram e para o aplicativo exclusivo para smartphones, chamado $\mathrm{CH}$ Week.
} 
a primeira página que a leitora tem contato com a revista - a capa - que iniciaremos os estudos das estratégias enunciativas que nos levarão a conhecer os objetos investidos de valor que o destinador-manipulador Capricho colocou em circulação, a partir do simulacro de leitor inscrito em seu fazer, de modo a persuadir o leitor a adquirir a revista, a acreditar no que está sendo dito e a levá-lo a agir de acordo com o que é proposto. Para tal empreendimento analítico, consideramos todos os 52 exemplares um enunciado único.

$\mathrm{Na}$ revista Capricho há uma interação entre diferentes linguagens de manifestações, que são a visual e a verbal, formando um todo de significação. Denomina-se esse texto-objeto de texto sincrético. Desse modo, não é possível apreender a significação do texto Capricho sem que haja uma articulação entre essas linguagens, portanto, não podemos analisar a dimensão plástica e os elementos nela presentes isoladamente, assim como os elementos verbais. Isso porque todos constituem escolhas do enunciador e constroem, em seu articular, um enunciado verbovisual, visando orientar a apreensão da significação por parte do enunciatário.

No suporte impresso, a organização da visualidade começa a ser delineada no projeto gráfico, concebido antes da publicação ser lançada no mercado. Esse projeto define como as páginas serão divididas, ou seja, seu número de colunas; os tipos e as características das letras; o alinhamento dos parágrafos, o posicionamento de fotos, fios, desenhos, logos e quadros. Porém, a cada exemplar esses elementos são organizados de modo diferente pela diagramação.

Diagramar é ordenar, organizar plasticamente nas páginas as fotografias, as matérias (textos jornalísticos), as legendas, os desenhos, as cores, enfim os elementos que constituem uma página impressa. Desse modo, reconhecemos que a articulação entre os elementos das linguagens verbal escrita e visual é promovida pela diagramação. As formas, as cores e a posição e distribuição desses na página (superfície matérica da revista) constituem, respectivamente, os formantes eidético, cromático, topológico e matérico do plano de expressão de um texto plástico. 


\section{A capa}

Por ser o "rosto" da publicação, onde são investidos os principais recursos gráficos e as temáticas que constituem a revista, a capa precisa impor sua presença na banca de revistas de modo a atrair a atenção do leitor, em especial, aquele ao qual se destina. Essa primeira página prenuncia um diálogo entre as manifestações verbais e visuais que está presente em toda a revista. Na capa da Capricho há a exploração de elementos plásticos e verbais familiares às jovens enunciatárias, que são distribuído e organizados, de acordo com o traçado do projeto gráfico. Desse modo, essa prática é uma das responsáveis pela construção da identidade da publicação, pois a torna reconhecível dentre tantas outras expostas na banca.

Impressa em papel couché brilhoso, $115 \mathrm{~g}$, por isso mais grossa e brilhosa que as páginas do miolo da revista (papel LWC 57g), a capa tem a sua visualidade e, portanto, a leitura da página, orientada por três elementos principais: o logotipo, o corpo das celebridades e o nome delas. No entanto, existem variabilidades e invariabilidades em relação a esses e outros elementos que a compõem.

Figura 1 - Elementos da capa da Capricho. 30 jan. 2011

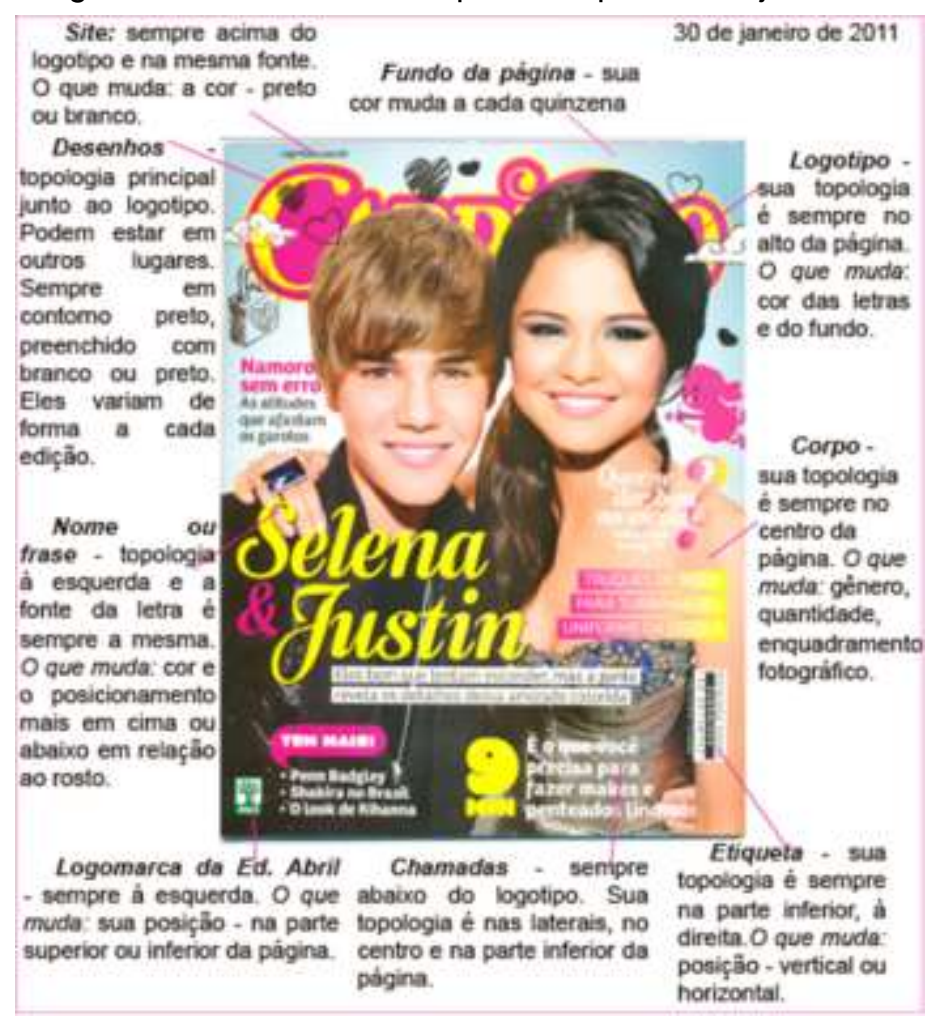

Fonte: arquivo pessoal da autora. 
O diálogo entre a publicação e o seu leitor é iniciado pelo logotipo. Localizado sempre na parte superior e em uma extensão que ocupa de um lado a outro da página, vem o nome da revista - CAPRICHO -, aliás, seu logotipo. Essa topologia é uma invariável na capa, no entanto, a cada exemplar as letras do logotipo e o fundo em que são grafadas mudam de cor. Escrito em letras de forma, suas serifas (hastes das letras) arredondadas, o prolongamento do traço do "R" até o início da letra "O" (ou seja, da esquerda para a direita) e do traço esquerdo do "H" até formar o pingo do "I" (mantendo o deslocamento da esquerda para a direita) proporcionam um efeito visual de movimento à palavra "Capricho".

No entanto, não é em toda edição que o logotipo aparece inteiramente. Nas 42 capas estudadas, o rosto da(s) personalidade(s), desenhos, círculos ou retângulos, que destacam em seu conteúdo o que a edição tem de especial ou as suas promoções, estão sobre algumas letras.

Apesar de todos esses elementos, o nome da revista mantém sua presença. Isso acontece porque a regularidade de sua topologia e do design de suas letras são marcas que constroem a leitura da palavra. Por sua vez, a recorrência da modificação cromática a cada edição e a aplicação de diferentes elementos gráficos sobrepostos às letras constituem uma estratégia plástica de referendar o estilo dinâmico e apurado da identidade de Capricho. Dessa constância, depreende-se um enunciador que zela para que o termo "Capricho" seja compreendido como uma ação realizada com esmero e primor em oposição a outra definição que o dicionário dá à palavra "Capricho": um fazer volúvel, que não segue regras, excêntrico. Essa exploração visual torna o logotipo um dos elementos de comunicação mais importante da publicação, pois sua iconização contagia os demais componentes da página e se expande para o conteúdo da publicação. A partir dele, tem-se, então, uma assinatura de quem enuncia e que o faz de modo a se posicionar enquanto um sujeito preocupado em valorizar o seu fazer euforicamente.

Também junto ao nome da revista, acima da letra "C", está o endereço eletrônico: capricho.com.br, e, às vezes, abaixo da mesma letra, a logomarca da empresa que a publica, Editora Abril. Esta também pode vir publicada na parte inferior da página, mas sempre do lado esquerdo. O site e a logomarca são figuras 
institucionais que ancoram e qualificam o modo de enunciar da Capricho. Ancoram porque concretizam no discurso os atores, os espaços e os tempos, levando a leitora a reconhecê-los como pertencentes ao mundo natural, produzindo o efeito de sentido de que as pessoas, os acontecimentos e os lugares existem, assim como existem a Editora Abril e o site. Assim, qualificam a Capricho como uma enunciadora que enuncia a verdade, que está acompanhando a evolução do seu tempo - por isso tem uma página na Internet - e que faz parte de uma grande empresa de comunicação. A Capricho não está sozinha. Ela pertence a uma família numerosa e com tradição no mercado editorial no Brasil.

Ao centro e ocupando verticalmente a Capa, tem-se sempre uma fotografia de celebridades, nacionais e internacionais: atores, atrizes, cantores, cantoras. Quando a pessoa famosa é estrangeira, as fotografias não são de autoria da revista, mas das assessorias de imprensa desses famosos. O crédito da foto de capa é informado no índice da revista. O enquadramento desses corpos ora são apresentados em close, destacando em seus rostos os olhos, as bocas, os cabelos; ou em contre-plongée, ora o corpo inteiro; ora o tronco.

O enquadramento em close constrói uma sintaxe plástica: a de que todas as capas com esse ângulo terão o nome da publicação diagramado sobre a testa da celebridade. Já, semanticamente, a exploração visual do logotipo promove um contágio estético entre ambas figuras (o logotipo e a celebridade), fazendo com que, em uma simbiose, ambos se tornem uma só celebridade. Esse contágio se expande ao leitor mediante o olhar desses jovens e da plasticidade do logotipo, colocando enunciador e enunciatário frente a frente, numa convocação para que este se aproxime dessa cena enunciativa. O procedimento plástico da horizontalidade do logotipo (Figura 2) leva o olhar a deslizar da esquerda para direita e em um alinhamento paralelo chega-se aos olhos dessas figuras, às maçãs da face, aos lábios e, então, o verbal complementa: "Quer beijar muito bem?” (7 de novembro de 2010), "Linda, já!" (20 de novembro de 2011). 
Figura 2 - Capas das edições de 7 nov. 2010 e 20

nov. 2011 recortadas na horizontal

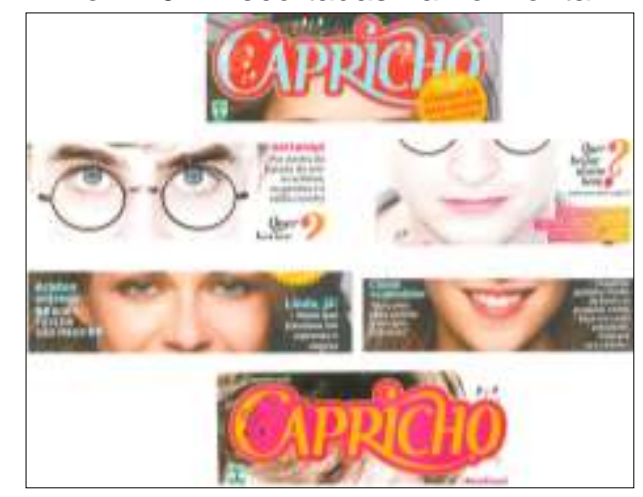

Fonte: arquivo pessoal da autora.

O sincretismo entre verbal e visual confirma a proposta de aproximação entre a revista/celebridade e a leitora. Landowski, em seu ensaio "Masculino, Feminino e Social" explica que algumas imagens,

[...] longe de atualizar o quer que seja, virtualizam a conjunção com o valor (ou a fusão com o objeto), remetendo-nos indefinidamente a uma outra coisa, a um gozo diferido e, afinal, a algum Outro cujo simulacro promissor elas constroem e com o qual fingem nos pôr em comunicação [...] (1998, p. 31).

É o enquadramento em close o agenciador dessa conjunção. Quando se trata de grupos musicais, todos os integrantes são fotografados em contre-plongée (quando o fotógrafo se posiciona um pouco abaixo ao sujeito a ser fotografado), em gestos descontraídos ou em poses tradicionais, isto é, alguns de pé e outros agachados olhando para frente. A exploração da horizontalidade e da verticalidade permanece, mesmo sendo mais de um corpo a compor a verticalidade e o nome da publicação estar por trás de tantas cabeças, de tantos corpos. É o efeito de perspectiva que sustenta essa categoria horizontal vs. vertical na dimensão plástica e, no plano do conteúdo, o dentro vs. fora da cena apresentada na capa. Horizontalmente, o logotipo e os olhares novamente trazem a leitora para junto dos grupos. Verticalmente a profundidade leva a leitora a "entrar" na página, metáfora visual para o "entrar" na revista. Ambas ações são confirmadas verbalmente pelas chamadas, por exemplo, mediante o uso do pronome pessoal "você", do pronome de tratamento "seu", de verbos na terceira pessoa do singular: "Linda no verão. Entre em forma e chegue bonita à areia [...]"; "Dudu, Caíque, Federico e Renan ajudam você a desvendar o que rola na cabeça dos meninos"; "14 truques espertos para salvar seu cabelo!". 
O enquadramento em contre-plongée também ocorre quando os personagens dos atores formam um casal nas histórias do cinema, da televisão ou na vida real. Eles apresentam-se abraçados. Essa pose convoca a leitora a ser espectadora da cena em que os casais trocam carícias, ficam lado a lado ou unem seus corpos em um abraço ou mãos nos ombros. A Capricho está lá, nos bastidores, ação figurativizada por sua localização atrás dos casais, para narrar os fatos sobre as suas vidas. Na edição de 21 de novembro de 2010, tem-se "Robsten no Brasil. A passagem do casal por aqui não deixa dúvidas: os dois estão mais apaixonados do que nunca". Nessa página, o coração no mesmo tom de rosa do fundo do logotipo confirma quem é esse narrador que apresenta à leitora uma "cobertura especial" a respeito do casal. Outro coração aparece na capa de 14 de julho de 2011, mas dessa vez está diretamente relacionado ao affair de "Diego e Roberta". Ao ser instalada enquanto espectadora, outra ação se estabelece para a leitora: a de ser espectadora cinematográfica e telespectadora de novelas e minisséries.

Os corpos, portanto, não são apenas de mulheres, como é comum em revistas destinadas ao público feminino. Ao todo foram 23 capas com os homens sozinhos, 20 capas com mulheres e 9 com casais. A maioria das pessoas fotografadas é branca; as duas exceções foram Rihanna (22 de maio de 2011) e Neymar (19 de junho de 2011). Ambos foram a segunda opção de capa para uma mesma edição. A leitora assinante não recebeu a capa com eles; em sua casa chegaram as capas com as meninas que compõem o grupo Rebelde! e Marina Ruy Barbosa, respectivamente.

Essas celebridades são figuras midiatizadas, ou seja, o seu modo de presença no mundo é mediado pelas tecnologias da informação. Segundo Sodré (2008, p. 21), "[...] midiatização é uma ordem de mediações socialmente realizadas no sentido de comunicação entendida como processo informacional, a reboque de organização empresariais e com ênfase num tipo particular de interação [...]". Portanto, compõe esse fluxo informacional os lançamentos de filmes, CDs, novelas, seriados, dentre outros produtos que influenciaram na seleção de algumas dessas figuras para compor as 52 capas analisadas. Todas as chamadas que acompanham essas figuras remetiam a algum evento ocorrido ou a acontecer, ou, então, informações sobre os personagens que desempenham na ficção cinematográfica ou televisiva. 
Enquanto mais um elemento da capa, essas figuras passam a ser também um recorte que a revista faz do mundo cultural a partir do simulacro de leitor construído no ato da composição visual da página. Por isso são jovens de ambos os sexos que figurativizam esse leitor, o seu tempo e o seu espaço. E para produzir a ilusão referencial, essas figuras estampam em seu rosto olhares doces, sedutores, sorrisos marotos, expressões de alegria, beijos na face, maquiagens, penteados, calça jeans, t-shirts, casacos, saias, minissaias, vestidos e bijuterias referentes à faixa etária, social e cultural da leitora. Ícones juvenis, esses corpos formam o eixo vertical da página, atraem a atenção da leitora e sustentam a proposta do logotipo da revista ao se apresentarem jovens, bem maquiados, penteados, sorridentes e saudáveis. Eles figurativizam uma edição feita com esmero (capricho).

Essa diagramação peculiar da capa que utiliza muitas cores, palavras, formas, rostos e corpos possui ainda outra assinatura: os pequenos desenhos. A forma e a cor desses elementos constroem o efeito de sentido de que foram feitos a lápis, espalhados pela capa, mas posicionados, às vezes, ao lado, acima ou abaixo de algumas palavras das chamadas. São desenhos de estrelas, corações, diamantes, florzinhas, sorvetes, nuvens, raios, dirigíveis enfim, ilustrações características de cadernos de adolescentes. Esses desenhos também são elementos gráficos da diagramação das matérias da revista.

Esses desenhos são mais um elemento da sintaxe que constrói a capa, mas o papel semântico que eles desempenham pode ser depreendido por sua constância na relação com os demais componentes. Então vejamos: a principal localização é no topo da página, próximo ao logotipo e, por conseguinte, ao rosto das celebridades. Os que mais se repetem são as estrelas e o desenho do coração.

Em 2011, identificamos 13 capas com estrelas e 16 com coração. Mas esses dois desenhos não compõem sozinhos uma única página. A combinação deles varia: coração com estrela e nuvem; estrela com raio e coração; estrela com diamante; estrela com nuvem. Esses conjuntos de desenhos reforçam semanticamente a foto da celebridade. As estrelas redundam o significado de essas personalidades pertencerem ao grupo sociocultural da fama. As estrelas e as nuvens, por serem elementos celestiais, quando junto a um ator ou cantor figurativizam o devaneio, o 
desligamento da realidade para o onírico. Quando essa dupla acompanha as atrizes ou cantoras, o eidético figurativiza delicadeza (nuvem) e glamour (estrela). O que se depreende do uso desses desenhos é que eles compõem um "alfabeto" visual, que é utilizado para enfatizar, reforçar os demais elementos que compõem a página: o logotipo, o corpo e as chamadas.

Para o enunciador, o verbal também é mais um constituinte plástico. Desse modo, os sentidos engendrados pela linguagem verbal tornam esse elemento ainda mais complexo. Os nomes das celebridades, por exemplo, possuem uma carga semântica extra ao serem grafados maiores e na cor das letras do logotipo. O efeito de sentido provocado por esse arranjo plástico sobre o verbal não é só o de um sucesso consagrado no mundo cultural pelo fazer fazer da celebridade, mas também um sucesso sancionado pela revista. E a recíproca é verdadeira. Ambos são celebridades, ambos figurativizam o sucesso, ambos sabem fazer ser e, portanto, expõem essa competência quinzenalmente de modo a mostrar o como a enunciatária deverá fazer para alcançar também o sucesso no que é proposto pela Capricho.

Portanto, o advérbio de modo mais utilizado é o "como". Ele é grafado nas chamadas de capa em tamanho maior que as demais palavras; também é cromatizado e topologicamente ocupa a linha superior à da chamada. Assim, ele atua enquanto título da chamada que o segue. O advérbio também pode ser encontrado no mesmo tamanho e cor das palavras das chamadas. "Como dar um beijo inesquecível" (16 de janeiro de 2011), "Ela conta como sua vida se transformou [...] (26 de setembro de 2010), RESOLVA SUA VIDA, Como não dormir na aula, fugir do tédio, ter um guardaroupa decente..." (9 de outubro de 2011). Às vezes o "como" não precisa vir escrito. Em algumas chamadas ele está pressuposto:

[...] Recurso de grande eficácia, o emprego retórico da pressuposição não é, porém, seu único uso persuasivo-argumentativo. Todo ato de pressupor implica presumir e, de alguma forma, impor a adesão do enunciatário. $\mathrm{Na}$ definição de Ducrot, o ato de pressupor mostra-se, claramente, como uma tática argumentativa. O enunciador obriga o enunciatário a admitir o conteúdo pressuposto, sem o que o discurso não prossegue, e não lhe dá o direito de discutir, de argumentar enfim, a partir de tal conteúdo. [...] (BARROS, 2001, p. 100). 
É o caso das chamadas quantitativas, pois elas apontam os modos de "como" encontrar produtos de beleza, de "como" se maquiar e se pentear, por exemplo. As gírias também são frequentes e não são grafadas em itálico ou entre aspas, como recomenda a norma culta. As mais publicadas na capa são: "dicas", "curtir", "mico", "rolar" e "balada". Porém, os estrangeirismos também podem ser classificados como "gírias", já que essas são, segundo Houaiss, "linguagem informal caracterizada por um vocabulário rico em idiomatismos metafóricos, jocosos, elípticos, ágeis e mais efêmeros que os da língua tradicional." Assim, Best Friends Forever (BFF), "look", "kit", "make", "love" compõem o léxico do enunciado verbal da capa como se fizessem parte da língua portuguesa.

\section{Sincretismo: ritmo, tempo e espaço}

O ritmo de leitura proposto é o da rapidez. Essa temporalidade é assegurada não só pelos formantes plásticos, mas também pelo verbal que compõe os enunciados. Os dêiticos "pro", "pra", "BFF", "MSN", "F5" e as frases curtas são alguns exemplos de dinamizadores de leitura que, em sincretismo com os constituintes plásticos, corroboram na construção de uma leitura de curta duração.

A temporalidade é uma das categorias enunciativas instauradas no enunciado pela enunciação e esta, por sua vez, é o lugar de instauração do sujeito que tem, em algum espaço, também sua referência. Como ocorrem as projeções da enunciação no enunciado capa? Nas 52 capas está presente o eu-aqui-agora, ou seja, estão instalados no enunciado os actantes da enunciação (eu/tu); o espaço da enunciação (aqui) e o tempo da enunciação (agora). A projeção dos actantes da enunciação na página se dá mediante o uso reiterado da segunda pessoa do singular (você) e do pronome possessivo na primeira pessoa do plural (nosso), que constroem um efeito de cumplicidade entre o enunciatário (a revista, que simula um "eu") e a enunciatária. A partir do recurso do discurso direto nas chamadas declarativas, cria-se o efeito de aproximação, de uma intimidade entre revista e leitora, uma vez que a Capricho cede espaço na página principal para delegar voz à sua leitora.

Esta leitora, por sua vez, também é instalada a partir de dois recursos visuais: do olhar frontal das celebridades, como um sujeito "em estado de comunicação" 
(LANDOWSKI, 1998) a convidar ou provocar um contato, um intercâmbio entre um eu e um tu; e da plasticidade dos desenhos, que constrói um efeito de convocação à leitora a também deixar o seu na página da revista. Ao se relacionar com esses elementos, a etiqueta também corrobora nessa instalação da leitora, seja enquanto assinante, seja enquanto compradora de banca. O "aqui" é o espaço da revista, ou seja, os conteúdos das chamadas deixam pressuposto que é no interior da revista que a leitora irá encontrar a matéria completa.

Revelam o tempo do "agora" os verbos conjugados no presente do indicativo, as gírias, as referências às redes sociais, os títulos dos filmes, das séries televisivas em cartaz e da falta de dêiticos temporais nas falas entre aspas. Na visualidade, o corpo é das celebridades que estão fazendo sucesso no período em que a publicação circula, as cores das letras seguem as paletas de cores da moda, assim como as roupas, os colares, as maquiagens e a data publicada na etiqueta.

O enunciado capa propõe, então, a interação entre a publicação e a leitora, sustentada pelo que aquela considera ser importante para esta. Ao dividir o espaço da página com a leitora, mediante os mecanismos de sua instalação, a revista a atrai para uma conversa sobre os temas atuais e pertencentes às configurações discursivas da jovem: informações sobre a vida das celebridades, moda e beleza, namoro e sexo. O modo de organizar esse enunciado a partir da reiteração dos elementos gráficos, das cores, dos corpos, da tipografia e das apresentações das chamadas conferem a Capricho um estilo próprio de se mostrar. O logotipo da publicação ratifica essa construção e dá unidade à plasticidade.

Dentre os elementos que não são constitutivos da capa estão os corpos de pele escura, corpos seminus, os não famosos (anônimos), uma linguagem formal e objetiva e uma diagramação clássica, onde os tipos gráficos não possuem serifas. Os textos são justificados, as vinhetas não apresentam uma forma arrojada e as cores são frias. Assim, as temáticas sobre política e economia não são publicadas na primeira página.

A sincretização das linguagens revela a performance de Capricho em fazer-se objeto modal para a sua enunciatária, portanto é importante ter a publicação para a leitora saber-ser a jovem da moda, enturmada e informada sobre modos de 
comportamento na vida social e íntima. Nessa relação intersubjetiva estão as táticas de manipulação que a sustenta: as de tentação e de sedução. A partir de elementos visuais e verbais que tentam a leitora e a induzem a acreditar que ela também pode ser competente, bastando para isso ler a "amiga" Capricho, a jovem, assim seduzida, realiza o fazer-interpretativo e o fazer-crer do destinador. Essa manipulação acontece porque a leitora, cognitivamente, crê nos valores da destinadora, pois compartilha do mesmo sistema axiológico articulado intencionalmente pela revista a partir do seu simulacro no ato de elaboração do enunciado. De posse desses valores, outras performances se realizam.

No entanto, para que esse programa de competências e, consequentemente, de performance seja concretizado, Capricho coloca em circulação objetos investidos de valores que provocam a jovem a desejá-los e, por fim, a realizar a performance de adquirir a revista, por meio da qual terá a competência do saber e do poder-fazer o que é proposto pela publicação. As informações sobre os produtos que estão na moda, preparativos para a festa de 15 anos, os segredos dos garotos, as dicas sobre sexo e relacionamento amoroso, sobre como superar e não provocar o bullying, os cuidados com as redes sociais, depoimentos de jovens que já são mães, de jovens que venceram uma etapa difícil da vida, enfim temáticas constitutivas do universo juvenil são os objetos de valores almejados pelas leitoras e que a revista coloca em circulação em diferentes narrativas engenhosamente bem diagramadas e discursivizadas de modo a construir, por meio de uma familiaridade visual e verbal, uma interação sensível.

Construímos então o enunciador e enunciatário desse texto Capricho: as jovens em busca de informações sobre como fazer para serem aceitas por seu grupo, serem entendidas por seus pais, terem um relacionamento amoroso, serem boas alunas e passarem de ano. A Capricho é a sua interlocutora, simula uma amizade e para isso apresenta-Ihe valores. Em se tratando da totalidade das edições, o modo recorrente como esses valores são apresentados em detrimento de outros que foram excluídos, a leitora inscrita não é aquela que quer ser, é aquela que deve ser segundo o que a Capricho considera ser ideal para ela. A partir dessa estabilidade no modo de dizer, depreendemos que o recorte de mundo natural feito pelo sujeito da enunciação é o de 
expor em suas capas os sujeitos midiatizados e abordar os temas sexo, beleza e relacionamento amoroso a partir desses sujeitos, que já estão realizados social e economicamente. Eles figurativizam que o sucesso pode ser obtido também na vida pessoal da leitora.

As celebridades, incluindo nelas, como vimos, a Capricho, é um conector isotópico que possibilita a passagem de uma leitura a outra em todos os exemplares da publicação. Para a semiótica, a isotopia é a reiteração dos temas e a recorrência das figuras no discurso. É ela quem garante a coerência textual. Desse modo, a coerência semântica e figurativa do texto Capricho é assegurada pela isotopia temática do sucesso e pela isotopia figurativa das celebridades, que nas seções Look e It Girl se desvelam e se assumem enquanto modelos a serem imitados.

Dos estudos da capa depreendemos que a revista propõe à leitora a busca pelo sucesso (pessoal e social) a partir do caminho indicado pela publicação. Por meio de uma visualidade alegre e de uma linguagem coloquial, cada passo desse caminhar é apontado com o uso do "você", como nas perguntas retóricas ("Como sobreviver a uma traição", 14 de março de 2010) e nas frases imperativas. Eis no nível discursivo, que a partir da capa começa a ser desenhada, a cena do ensinamento didático que é próprio do gênero cartilha.

A capa preanuncia não apenas o conteúdo da publicação, mas também o como esse conteúdo virá expresso. A diagramação trata-se, portanto, de uma estratégia enunciativa que permite a leitora já entrever o que será apresentado nas páginas da revista a partir da apreensão sensível da sua capa. O cromático, o eidético, o topológico, o léxico e os temas da primeira página são o diapasão que a cada edição ordena o arranjo estético da plástica sincrética e a axiologia do texto Capricho ao homologarem-se com o arranjo do plano de conteúdo.

O sincretismo das linguagens verbal e visual constrói uma memória textual tecida pelas reminiscências de imagens e palavras redundantes em todos os exemplares e que são constitutivas do conjunto plástico e temático que norteia a linha gráfica e editorial da revista. Seu estudo mostra a relevância das análises das relações entre o visual e o verbal escrito, como no presente caso, para a apreensão 
da significação de um texto sincrético. Essa prática de leitura também corrobora na construção de um sujeito-leitor capaz de entender que os arranjos visuais "falam" tanto quanto as palavras neles inscritas.

\section{Referências}

BARROS, Diana Luz Pessoa de. Teoria do discurso: fundamentos semióticos. 3. ed., São Paulo: Humanitas/FLLCH/USP, 2001.

LANDOWSKI, Eric. Masculino, feminino, social. Nexos: Revista de Estudos de Comunicação e Educação - Semiótica, mídia e arte, ano 2, n. 3, p. 13-43, ago. 1998.

SODRÉ, Muniz. Antropológica do espelho: uma teoria da comunicação linear e em rede. 3. ed. Petrópolis, RJ: Vozes, 2008.

\section{Letícia Nassar Matos Mesquita}

Mestre em Comunicação e Semiótica pela Pontifícia Universidade de São Paulo (COS/PUC/SP); Doutora em Educação: linguagens verbal e visual pela Universidade Federal do Espírito Santo (PPGE/UFES); jornalista da Superintendência de Cultura e Comunicação da UFES; Grupo de Pesquisa de Processos Educativos da Arte - GEPEL da UFES e membro do Centro de Pesquisas Sociossemióticas (CPS/PUC/SP).

E-mail: letty3@yahoo.com

Currículo: http://lattes.cnpq.br/3501642639807824

\section{Moema Lucia Martins Rebouças}

Mestre em Educação pelo Programa de Pós-Graduação em Educação da Universidade Federal do Espírito Santo (UFES); Doutora em Comunicação e Semiótica pela Pontifícia Universidade de São Paulo (COS/PUC/SP); Pós-Doutora pela Faculdade de Belas Artes da Universidade do Porto; Professora Associada da UFES; pesquisadora do CNPq, líder do Grupo de Pesquisa de Processos Educativos da Arte - GEPEL da UFES e membro do Centro de Pesquisas Sociossemióticas (CPS/PUC/SP).

E-mail:moemareboucas@gmail.com

Currículo: http://lattes.cnpq.br/4414451806305375 